Article

\title{
Construction of Polymer Electrolyte Based on Soybean Protein Isolate and Hydroxyethyl Cellulose for a Flexible Solid-State Supercapacitor
}

\author{
Zhiyu Xun ${ }^{1,2,+}$, Shoupeng Ni ${ }^{1,2,+}$, Zhenhua Gao ${ }^{1,2} \mathbb{D}$, Yanhua Zhang ${ }^{1,2}$, Jiyou Gu ${ }^{1,2, *}$ \\ and Pengfei Huo 1,2,* \\ 1 Materials Science and Engineering College, Northeast Forestry University, Harbin 150040, China; \\ 15963729607@163.com (Z.X.); nisp2019@163.com (S.N.); gaozh1976@163.com (Z.G.); \\ zhangyanhua@nefu.edu.cn (Y.Z.) \\ 2 Key Laboratory of Bio-based Materials Science \& Technology (Northeast Forestry University), \\ Ministry of Education, Harbin 150040, China \\ * Correspondence: dldgujy@nefu.edu.cn (J.G.); huopengfei@nefu.edu.cn (P.H.); \\ Tel.: +139-4505-3580 (J.G.); +187-4500-0374 (P.H.) \\ + These two authors contributed equally to this work and should be considered co-first authors.
}

Received: 9 October 2019; Accepted: 14 November 2019; Published: 17 November 2019

\begin{abstract}
Supercapacitors are a very active research topic. However, liquid electrolytes present several drawbacks on security and packaging. Herein, a gel polymer electrolyte was prepared based on crosslinked renewable and environmentally friendly soybean protein isolate (SPI) and hydroxyethyl cellulose (HEC) with $1.0 \mathrm{~mol} \mathrm{~L}^{-1} \mathrm{Li}_{2} \mathrm{SO}_{4}$. Highly hydrophilic SPI and HEC guaranteed a high ionic conductivity of $8.40 \times 10^{-3} \mathrm{~S} \mathrm{~cm}^{-1}$. The fabricated solid-state supercapacitor with prepared gel polymer electrolyte exhibited a good electrochemical performance, that is, a high single electrode gravimetric capacitance of $91.79 \mathrm{~F} \mathrm{~g}^{-1}$ and an energy density of $7.17 \mathrm{~W} \mathrm{~h} \mathrm{~kg}^{-1}$ at a current density of $5.0 \mathrm{~A} \mathrm{~g}^{-1}$. The fabricated supercapacitor exhibited a flexible performance under bending condition superior to liquid supercapacitor and similar electrochemical performance at various bending angles. In addition, it was proved by an almost $100 \%$ cycling retention and a coulombic efficiency over 5000 charge-discharge cycles. For comparison, supercapacitors assembled with commercial aqueous PP/PE separator, pure SPI membrane, and crosslinked SPI membrane were also characterized. The obtained gel polymer electrolyte based on crosslinked SPI and HEC may be useful for the design of advanced polymer electrolytes for energy devices.
\end{abstract}

Keywords: gel polymer electrolyte; soybean protein isolate; hydroxyethyl cellulose; solid-state supercapacitors

\section{Introduction}

Supercapacitor (SC) is considered as an electrochemical energy storage device with a great potential due to its high-power, long cycle life, low environmental impact, and high safety at present [1]. Recently, the development of flexible solid-state supercapacitors fabricated with polymer electrolytes that can be used in wearable electronic devices has attracted more attention.

It is well known that the energy density of a supercapacitor is determined by the specific capacitance and squared operating voltage window [2,3]. To improve the energy density, tremendous efforts have been devoted to developing novel electrode materials to elevate the specific capacitance [4-10]. Apart from the electrodes, electrolyte is one of the key components of a supercapacitor, that can significantly affect the operating voltage as well as lifespan and safety of supercapacitors [11-13]. The supercapacitors assembled with liquid electrolytes have the disadvantages of electrolyte leakage, 
high packaging costs, and usually being toxic or corrosive, which limits their application for portable electronic devices [14].

The design and development of polymer electrolytes have been attracting much attention due to excellent safety, stability, flexibility, etc., which make them widely used in various electronic devices such as lithium-sulfur batteries, lithium-metal batteries, lithium-ion batteries, fuel cells, and supercapacitors [15-22]. Piana et al. reported poly(ethylene oxide) (PEO)/ $\mathrm{Li}_{1.5} \mathrm{~A}_{10.5} \mathrm{Ge}_{1.5}\left(\mathrm{PO}_{4}\right)_{3}$ hybrid solid polymer electrolytes for super $\mathrm{Li}^{+}$ion conducting ceramic with high ionic conductivity and excellent Coulombic efficiency (>99.5\%) under high current regimes [16]. A 3D GPE based on poly(vinylidene fluoride-hexafluoro propylene) (PVDF-HFP) with polymerized pentaerythritol tetrakis-divinyl adipate was prepared and could suppress Li dendrites growth in lithium-sulfur batteries [18]; Wang et al. prepared epoxy based adhesive polymer electrolyte with high ionic conductivity $\left(>10^{-2} \mathrm{~S} \mathrm{~cm}^{-1}\right)$ for a solid-state supercapacitor [20]. In summary, polymer electrolytes can replace liquid electrolytes and serve as both separator and electrolyte with a high ionic conductivity at ambient temperature, good mechanical strength, excellent stability, and a wide potential window in energy devices [23]. Polymer electrolytes can be classified into solid polymer electrolytes (SPEs) and gel polymer electrolytes (GPEs). SPEs mostly deliver low ionic conductivities $\left(10^{-8}-10^{-5} \mathrm{~S} \mathrm{~cm}^{-1}\right)$ and poor interfaces with electrodes, resulting in deteriorated cycle performance [24-27]. GPEs have been extensively investigated because they can deliver an ionic conductivity as high as liquid electrolyte and provide a variety of potential advantages, including good interfacial contact with electrodes, higher safety and adaptability, and flexibility for flexible energy storage devices [28-30].

GPE can be prepared by assembly of polymer skeleton and supporting liquid electrolyte. The polymer substrate plays an important role in a GPE. However, non-degradable synthetic polymer materials in GPE face several disadvantages and are not environmentally friendly. Hence, it is imperative to develop biopolymer electrolytes by using natural polymers, which have gained more and more attention, owing to their abundance in nature, low cost, friendliness to the environment, and potential as substitute for some petrochemicals [31]. Biomass materials—such as cellulose, chitosan, soybean protein, etc.- are of concern for their regenerability and degradation in nature.

As a biomass material, soybean protein isolate (SPI), a byproduct of the soybean oil industry, has been applied in many fields including energy storage due to its renewability, biocompatibility, biodegradability, processability, and film-forming capacity [32], and the ionic protein containing different types of amino acids can be used to transport ions for energy storage devices [33]. Zhu et al. prepared porous membranes with SPI and PVA via electrospinning as separators for lithium ion batteries [34]. A composite GPE was constructed from porous polydopamine spheres and SPI membrane to suppress Li dendrite growth and trap manganese ions for a high-performance Li battery [35]. These studies demonstrate that SPI can be used as a polymer matrix for polymer electrolyte; furthermore, SPI contains abundant polar functional groups to obtain excellent hydrophilicity, which provides the membrane with a good electrolyte affinity. However, the application remains substantially limited due to the high-water sensitivity, undesirable processability, and inferior mechanical strength [36]. A lot of investigations on modification of SPI have been carried out to solve the problems mentioned above [37-39]. In our previous work, a series of crosslinked membranes was prepared by SPI crosslinked with ethylene glycol diglycidyl ether (EGDE) as the crosslinker and it was found that the crosslinked structure could improve the water resistance of SPI/EGDE membrane, but it also reduced the ionic conductivity of the pure SPI film and electrochemical performance of the supercapacitor [40].

To improve the decline in electrochemical performance due to the crosslinked membrane and maintain good water resistance, a highly hydrophilic polymer can be introduced into the crosslinked structure to construct a composite system. Hydroxyethyl cellulose (HEC), a derivative of cellulose, has a wide range of sources [41]. HEC has excellent hydrophilicity and been widely used as a water-soluble additive. Simultaneously, it has other characteristics, such as film-forming capacity similar to cellulose. Moreover, HEC can interact with polar groups such as amino groups and carboxyl groups on SPI to form a uniform and stable film material [42]. 
In this study, a series of membranes was prepared by SPI as the polymer matrix, blended with HEC and crosslinked by ethylene glycol diglycidyl ether (EGDE) which is an epoxy compound with low toxicity. The crosslinked membranes were then saturated with $1.0 \mathrm{M} \mathrm{Li}_{2} \mathrm{SO}_{4}$ electrolyte with a large operating potential window to form gel polymer electrolytes (GPEs) and applied in solid-state supercapacitors (SSCs). The comprehensive properties of the membranes, GPEs, and SSCs were systematically investigated. The membrane based on the crosslinked SPI and HEC not only maintains its water resistance, but also improves the ionic conductivity of GPE and electrochemical performance of supercapacitor.

\section{Materials and Methods}

\subsection{Materials}

SPI (96.5 wt \%) was purchased from Harbin Gaoke Food Technology Co., Ltd. (Harbin, China). HEC was obtained from Aladdin Industrial Corporation. Glycerin (analytical grade) was acquired from Guangfu technology development Co., Ltd. (Tianjin, China). Activated carbon (AC) and acetylene black (battery grade) were provided by Japan KURARAY (Shanghai, China) and Crisco Chemical Technology Co., Ltd. (Shanghai, China), respectively. EGDE and polytetrafluoroethylene (PTFE) (60 wt \%) concentrate were purchased from Aladdin Reagent (Shanghai, China) Co., Ltd. (Shanghai, China). Nickel foam was purchased from Kejing Zhida Co., Ltd. (Shenzhen, China). Anhydrous lithium sulfate and commercial hydrophilic PP/PE composite membrane were received from Saen Chemical Technology Co., Ltd. (Shanghai, China) and Lizhiyuan Battery Co., Ltd. (Taiyuan, China) respectively.

\subsection{Preparation of Gel Polymer Electrolyte Based on Crosslinked SPI and HEC}

SPI powder was dispersed in deionized water and stirred constantly to form a suspension. Glycerol was added and the $\mathrm{pH}$ of suspension was adjusted to 10, after which the suspension was stirred for $30 \mathrm{~min}$ at room temperature followed by being heated at $85{ }^{\circ} \mathrm{C}$ under constant stirring for $30 \mathrm{~min}$. The suspension was then cooled down to room temperature and ultrasonicated for $10 \mathrm{~min}$. Finally, a $5 \mathrm{wt} \%$ SPI solution was obtained. The HEC powder was dissolved in deionized water to form a $5 \mathrm{wt} \%$ solution simultaneously. The SPI solution and HEC solution were mixed for $2 \mathrm{~h}$. The crosslinker EGDE was dropped into the solution and stirred for $1 \mathrm{~h}$. In order to maintain a similar degree of crosslinking of each membrane, equal amount of crosslinker EGDE was added in the membranes of the same quantity. The homogeneous solution was cast onto a dry flat glass plate and dried at $50{ }^{\circ} \mathrm{C}$ for $24 \mathrm{~h}$. The membrane based on crosslinked SPI and HEC was peeled off and recorded as MCM-H. SPI membrane named MCM-S and crosslinked SPI membrane named MCM-E were prepared in a similar process described above. For comparison, the commercial hydrophilic $\mathrm{PP} / \mathrm{PE}$ membrane was used as a separator and named MCM-C. The component information was listed in Table 1. All the membrane samples were immersed in $1.0 \mathrm{M} \mathrm{Li}_{2} \mathrm{SO}_{4}$ electrolyte to form GPEs named GPE-H, GPE-S, GPE-E, and GPE-C, respectively.

Table 1. Component information of the prepared modified membranes.

\begin{tabular}{ccccc}
\hline Samples & SPI (5 wt \% Solution, $\mathbf{g})$ & Glycerol $(\mathbf{g})$ & EGDE $(\mathbf{g})$ & HEC $(\mathbf{5} \mathbf{w t} \%$ Solution, $\mathbf{g})$ \\
\hline MCM-S $^{\mathrm{a}}$ & 12 & 0.3 & 0 & 0 \\
MCM-E $^{\mathrm{b}}$ & 12 & 0.3 & 0.12 & 0 \\
MCM-H $^{\mathrm{c}}$ & 8.4 & 0.21 & 0.12 & 3.6 \\
\hline${ }^{\mathrm{a}}$ The pure SPI membrane; ${ }^{\mathrm{b}}$ The crosslinked SPI membrane; ${ }^{\mathrm{c}}$ The crosslinked SPI membrane with HEC.
\end{tabular}

\subsection{Fabrication of SSCS}

Firstly, the AC electrodes were prepared by $80 \mathrm{wt} \%$ AC powder, $10 \mathrm{wt} \%$ acetylene black and $10 \mathrm{wt}$ $\%$ PTFE, and each electrode was $4.1 \mathrm{mg}$. The SSCs were then assembled as the following sandwiched structure: AC electrode//GPE//AC electrode and simply packaged. The process was described as 
shown in Figure 1. For comparison, a SSC with GPE-C was also fabricated by the same method and recorded as SSC-C. The flexibility of supercapacitor was named SSC- $\mathrm{H}^{\prime}$ and tested by assembling polymer electrolyte and electrodes with area of $3 \mathrm{~cm}^{2}(1 \times 3 \mathrm{~cm})$.

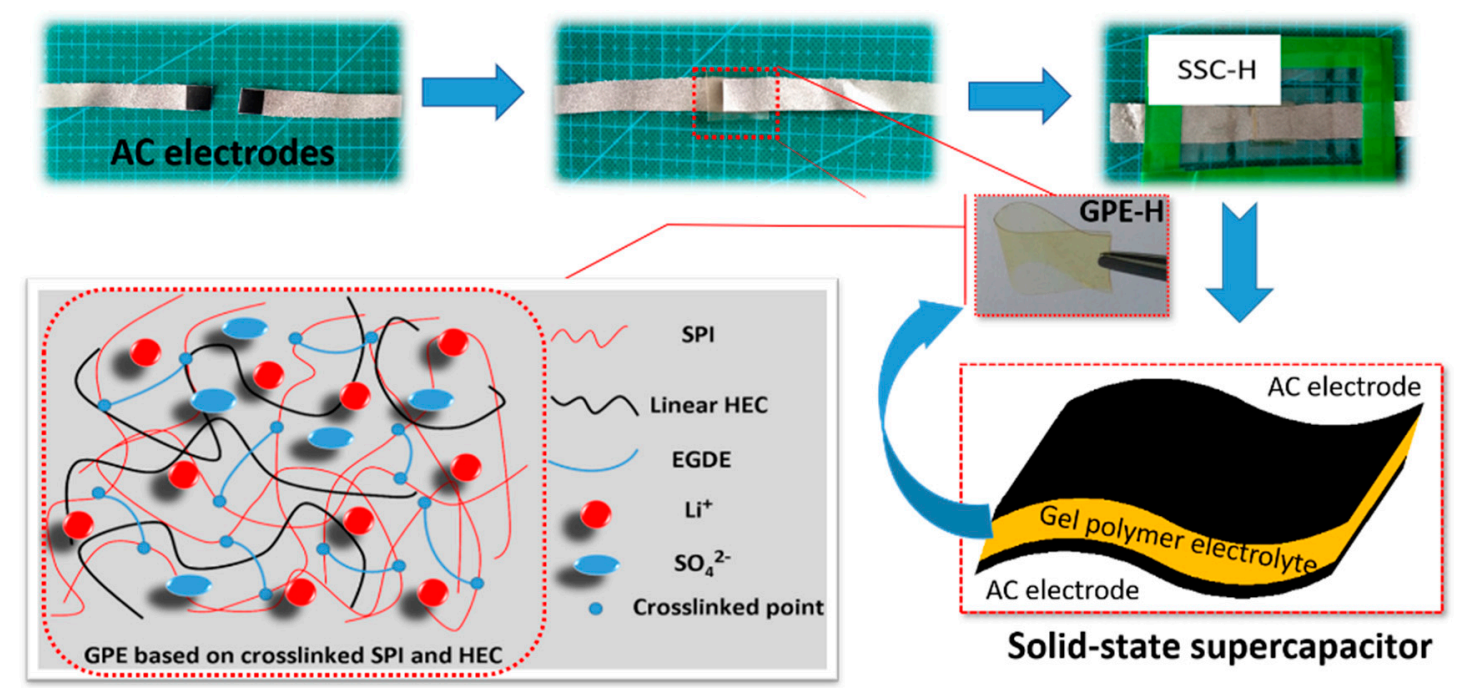

Figure 1. Schematic illustration of the assembly process of SSC and schematic diagram of crosslinked based on SPI and HEC.

\subsection{Characterization of Membrane Samples}

The ATR-FTIR spectra of all the samples were recorded from 500 to $4000 \mathrm{~cm}^{-1}$ using a Spectrum One FTIR spectrophotometer (Nicolet Co., Madison, WI, USA). XRD of samples were evaluated with a D/max-2 200 diffractometer (Rigaku International Corporation, Tokyo, Japan). X-ray radiation was generated from a Cu-K $\alpha$ source at an accelerating voltage of $40 \mathrm{kV}$ and a current of $30 \mathrm{~mA}$. The diffraction data were collected from $5^{\circ}$ to $50^{\circ}$ with a step interval of $0.02^{\circ}$. Thermogravimetric analysis (TGA) of samples were analyzed using a Netzsch 209 F3 TGA instrument (NET Scientific Instruments Trading (Shanghai) Co., Ltd., Shanghai, China) under a Nitrogen atmosphere from $30^{\circ} \mathrm{C}$ to $600{ }^{\circ} \mathrm{C}$ at a heating rate of $10{ }^{\circ} \mathrm{C} \mathrm{min}^{-1}$.

\subsection{Electrolyte Uptake of Membranes}

Membrane samples $(1.5 \times 4.0 \mathrm{~cm})$ were dried at $80^{\circ} \mathrm{C}$ for $24 \mathrm{~h}$ to a constant weight which was recorded as $W_{d r y}$. The dry membrane was immersed in $1.0 \mathrm{M} \mathrm{Li}_{2} \mathrm{SO}_{4}$ for $30 \mathrm{~min}$ at room temperature, followed by wiping with filter paper for removal of excess $\mathrm{Li}_{2} \mathrm{SO}_{4}$ solution on the surface, the weight of the wet membrane was recorded as $W_{\text {wet }}$. The electrolyte uptake (EU) was calculated by the equation.

$$
\text { EU }(\text { Electrolyte uptake })(\mathrm{wt} \%)=\frac{W_{\text {wet }}-W_{d r y}}{W_{d r y}} \times 100 \%
$$

Five replicates were performed for each membrane.

\subsection{Ionic Conductivity of GPES}

The ionic conductivity $\left(\sigma, \mathrm{S} \mathrm{cm}^{-1}\right)$ of the GPEs can be calculated by the equation.

$$
\sigma=\frac{L}{R_{b} \times S}
$$

where $L(\mathrm{~cm})$ is the thickness of the GPE, $S\left(\mathrm{~cm}^{2}\right)$ is the effective interface area between GPE and stainless-steel electrode. $R_{b}(\mathrm{ohm})$ is the bulk resistance of the GPE and measured by electrochemical impedance spectroscopy (EIS) measurement with a potential amplitude of $10 \mathrm{mV}$ and a frequency range 
from $1 \mathrm{~Hz}$ to $100 \mathrm{kHz}$ by using electrochemical workstation (CHI660B, Shanghai, China). In order to establish the relationship between the ionic conductivity of GPE and the electrochemical performance of the corresponding SSC, only one set of data for each GPE and corresponding solid-state supercapacitor is used and discussed.

\subsection{Electrochemical Characterization of SSCs}

The electrochemical performance of the SSCs with different GPEs was investigated in a two-electrode system by EIS, cyclic voltammetry (CV) and galvanostatic charge-discharge (GCD) techniques by using electrochemical workstations (CHI660B, Shanghai, China). The EIS spectrum was used to analyze the impedance behavior of the single cell with frequency range from $0.01 \mathrm{~Hz}$ to $100 \mathrm{kHz}$ at the amplitude of open-circuit voltage. CV tests of the solid-state supercapacitors were conducted within a stable potential window $(0-1.5 \mathrm{~V})$ at different scan rate $\left(10,20,50,100,200 \mathrm{mV} \mathrm{s}^{-1}\right)$. GCD characterization was conducted within a stable potential window $(0-1.5 \mathrm{~V})$ at different current density $\left(1,2,5,10 \mathrm{~A} \mathrm{~g}^{-1}\right)$. GCD measurement was used to determine the capacitance and the cycle performance of cells. The single electrode gravimetric specific capacitance $\left(C_{s p}, \mathrm{~F} \mathrm{~g}^{-1}\right)$ was calculated from the GCD curves according to the equation.

$$
C_{s p}=\frac{4 I}{m} \times \frac{d t}{d v}
$$

where $I$ is the constant current $(\mathrm{A}), m$ is the $\mathrm{AC}$ mass of two electrodes $(\mathrm{g}), d v / d t\left(\mathrm{~V} \mathrm{~s}^{-1}\right)$ is the slope of the fitting straight line to the discharge curve excluding the IR drop. The energy density $\left(E_{c e l l}, \mathrm{~W} \mathrm{~h} \mathrm{~kg}^{-1}\right)$ and power density $\left(P_{\text {cell }}, \mathrm{W} \mathrm{kg}^{-1}\right)$ of SSC were calculated as.

$$
\begin{gathered}
E_{\text {cell }}=\frac{C V^{2}}{2}=\frac{C_{s p} V^{2}}{8} \\
P_{\text {cell }}=\frac{E_{\text {cell }}}{\Delta t}
\end{gathered}
$$

where $V$ is the cell voltage without voltage drop, $\Delta t$ is the discharge time.

The electrochemical cycling life of the SSC-H was investigated for 5000 charge and discharge cycles at a current density of $2 \mathrm{~A} \mathrm{~g}^{-1}$ by using LAND test equipment (LAND, CT3001A, Wuhan, China).

\section{Results and Discussion}

\subsection{Structural Analysis of Membrane Samples}

The ATR-FTIR spectra of HEC powder, MCM-S, MCM-E, and MCM-H are shown in Figure 2. The adsorption band at $3000-3500 \mathrm{~cm}^{-1}$ and about $2900 \mathrm{~cm}^{-1}$ were attributed to the free bound $-\mathrm{OH}$ and $-\mathrm{CH}_{3}$ and $-\mathrm{CH}_{2}-$ in the prepared membranes, respectively. The absorption peaks of characteristic group of protein were observed at $1626 \mathrm{~cm}^{-1}, 1537 \mathrm{~cm}^{-1}$, and $1223 \mathrm{~cm}^{-1}$ and correspond to amide I ( $\mathrm{C}=\mathrm{O}$ stretching vibration), amide II ( $\mathrm{N}-\mathrm{H}$ bending vibration), and amide III ( $\mathrm{C}-\mathrm{N}$ stretching and $\mathrm{N}-\mathrm{H}$ bending vibration), which were consistent with a previous report [43]. The $\mathrm{COO}-$ and $-\mathrm{C}-\mathrm{NH}_{2}$ absorption peaks could be observed at $1396 \mathrm{~cm}^{-1}$ and $1036 \mathrm{~cm}^{-1}$, respectively [44,45]. From Figure $2 \mathrm{~b}$, it can be observed that the introduction of HEC, the absorption peak of amide II $\left(1537 \mathrm{~cm}^{-1}\right)$ shifted to $1556 \mathrm{~cm}^{-1}$, which was due to the hydrogen bond interaction between HEC and SPI. 

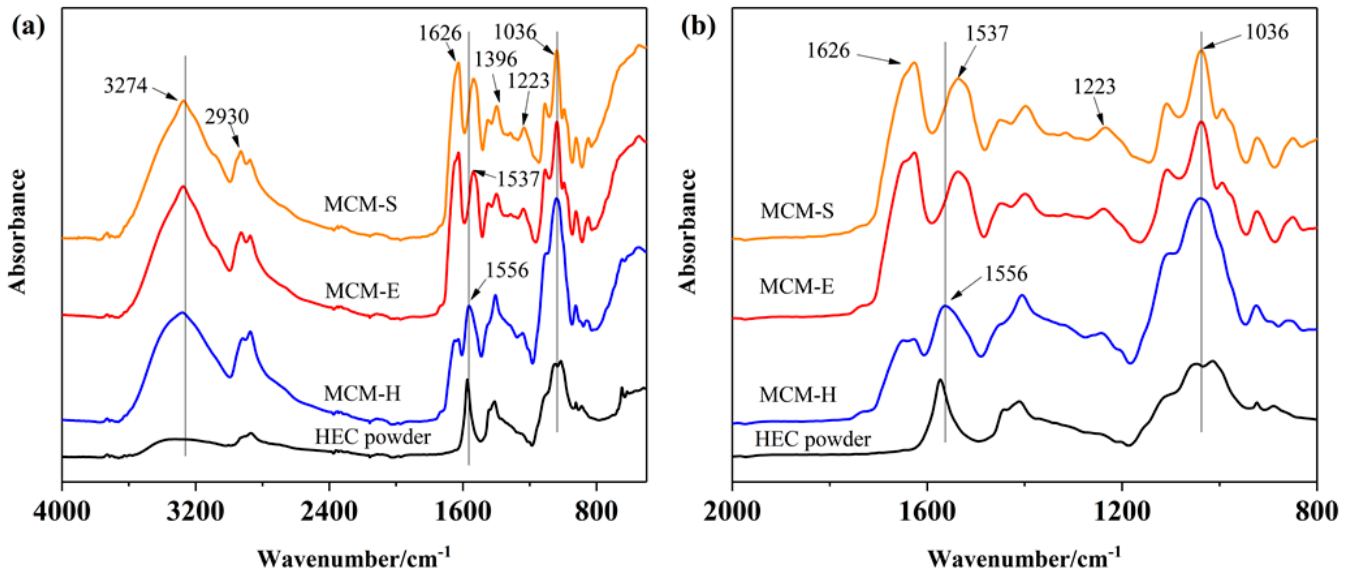

Figure 2. (a) ATR-FTIR spectra of HEC powder, MCM-S, MCM-E, MCM-H from 500 to $4000 \mathrm{~cm}^{-1}$, (b) ATR-FTIR spectra from 800 to $2000 \mathrm{~cm}^{-1}$.

XRD patterns of pure SPI power and membrane samples are shown in Figure 3. Characteristic diffraction peaks at $2 \theta \approx 9.3^{\circ}$ and $19.3^{\circ}$ of the pure SPI power represent the $\alpha$-helix and $\beta$-sheet structures of SPI secondary structure, respectively [46]. It is obvious that these two characteristic diffraction peaks can be found in MCM-S. With the addition of EGDE, the characteristic absorption peak at $2 \theta \approx 9.3^{\circ}$ of MCM-E disappeared, which indicates that a chemical reaction occurred between EGDE and SPI. The XRD curves of MCM-E and MCM-H are almost the same, indicating that high compatibility between SPI and HEC.

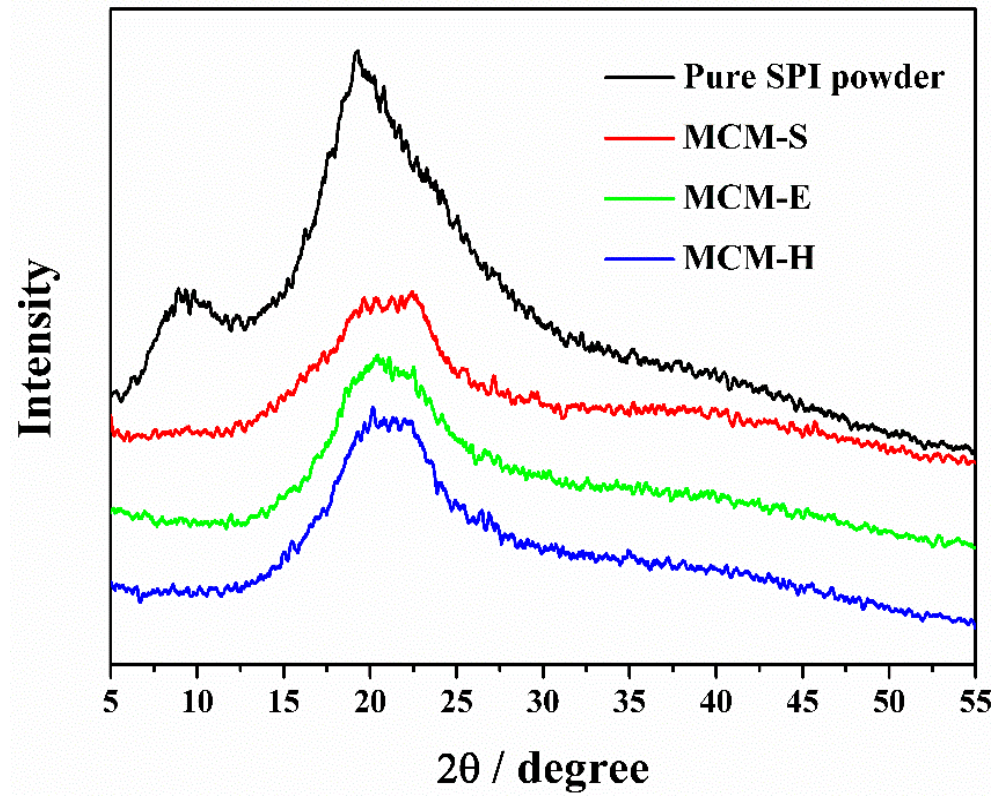

Figure 3. XRD patterns of SPI power and membrane samples.

\subsection{Thermal Stability}

Thermal stability of samples was investigated using TGA. The TGA curves recorded from $30{ }^{\circ} \mathrm{C}$ to $600{ }^{\circ} \mathrm{C}$ are shown in Figure 4. Only one decomposition stage can be observed for thermal decomposition of the SPI powder. The initial degradation and the maximum decomposition rate of SPI powder occurred at around $200^{\circ} \mathrm{C}$ and $310^{\circ} \mathrm{C}$. Initial decomposition of modified SPI membranes occurred at around $125^{\circ} \mathrm{C}$, which is lower than that of the SPI powder, which may be due to partial degradation of the SPI molecular structure caused by $\mathrm{KOH}$ and glycerol. Decomposition temperature 
of MCM-H is higher than MCM-S and MCM-E from the beginning to the end of thermal decomposition. Maximum decomposition rate temperature of MCM-E is significantly higher than MCM-S and is even higher than that of SPI powder. Although the maximum decomposition rate temperature of MCM-H is slightly lower than that of MCM-E, it is still higher than that of MCM-S, which indicates that the crosslinked structure can significantly improve the thermal stability of MCM-H membrane.

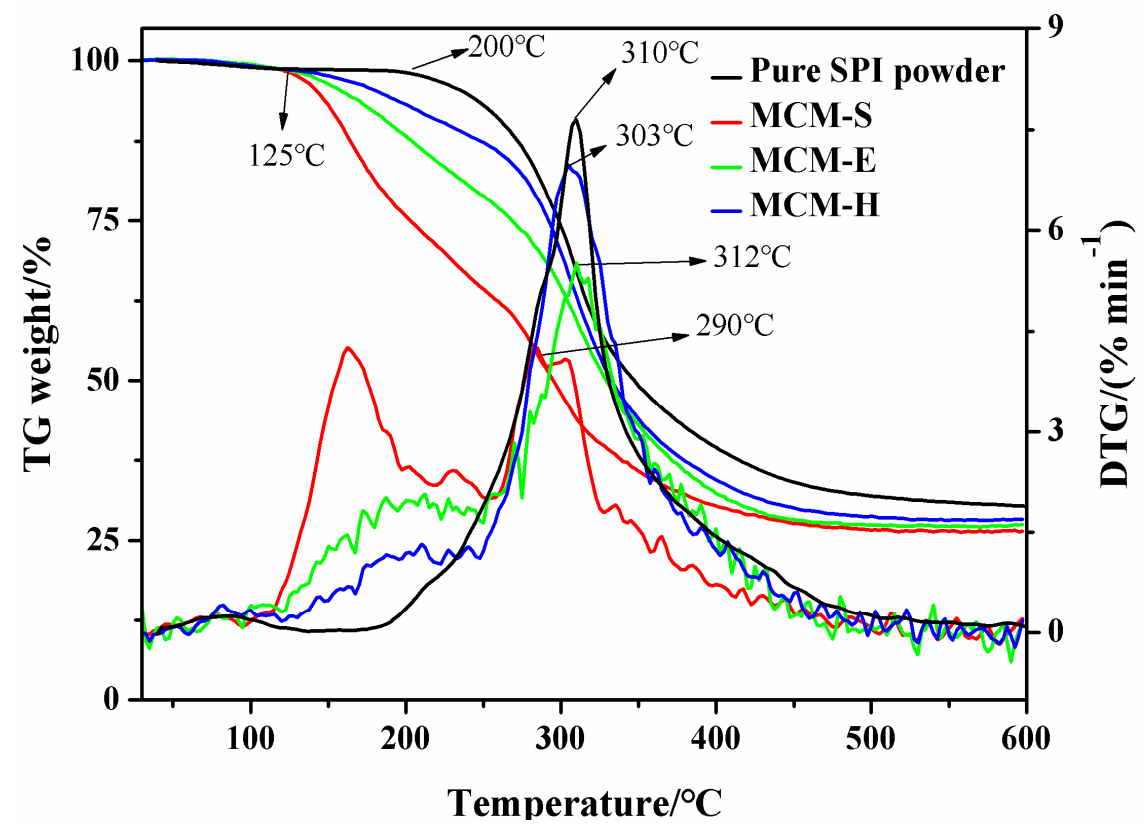

Figure 4. TG and DTG patterns of SPI powder and membrane samples.

\subsection{Electrolyte Uptake, Water Resistance of Membrane Samples, and Ionic Conductivities of GPEs}

The Nyquist plots of GPEs are shown in Figure $5 a, b$. The Ionic resistance $\left(R_{b}\right)$ can be determined by the intersection of the Nyquist plot and the $Z^{\prime}$ axis in high frequency area. The ionic conductivities of GPEs can be calculated and displayed in Table 2. The lower ionic conductivity of GPE-E resulted from the consumption of the hydrophilic amino groups in the SPI via the crosslinking reaction with EGDE. GPE-H has a higher ionic conductivity and electrolyte uptake than GPE-S and GPE-E. The addition of hydrophilic HEC compensates for the loss of hydrophilic functional groups due to crosslinking reaction and due to HEC facilitating the transport of electrolyte ions, which can be obviously observed from the electrolyte uptake results in Figure 5c. SPI membrane has a good ionic conductivity due to the good hydrophilicity as well as ionic property to facilitate the ion transport of the polymer electrolyte. This is an important factor in the selection of SPI as a polymer matrix of polymer electrolyte. Furthermore, comparison between GPE-H and GPE-C was carried out. GPE-C exhibits a higher ionic conductivity due to the high porosity facilitating the transport of ions. 

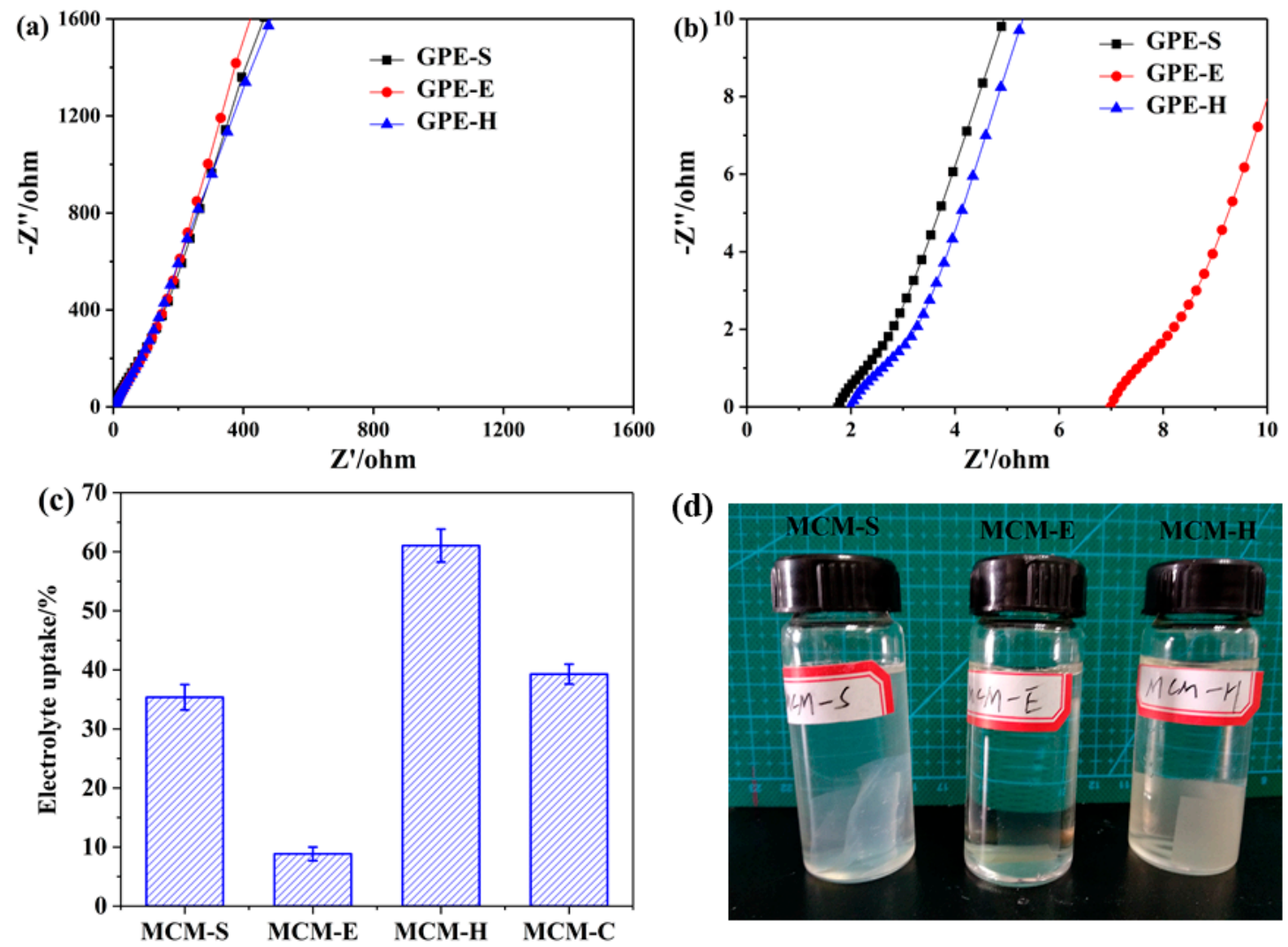

(d)

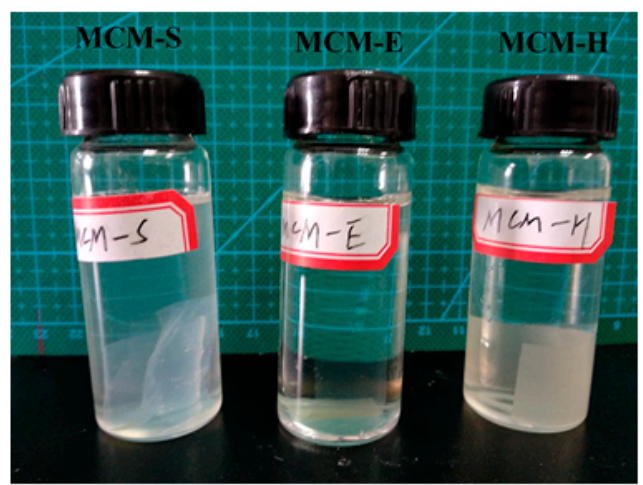

Figure 5. (a) Nyquist plots of GPEs, (b) the high frequency region of the Nyquist plots, (c) the electrolyte uptake of GPEs, and (d) water resistance of membrane samples.

Table 2. Electrolyte uptakes of membrane samples and thickness, ionic conductivities of GPEs.

\begin{tabular}{ccccc}
\hline GPE Sample & $\begin{array}{c}\text { Thickness of } \\
\text { GPEs } \mathbf{( c m )}\end{array}$ & $\begin{array}{c}\text { Ionic Conductivity } \\
\mathbf{( 1 0}^{-\mathbf{3}} \mathbf{S} \mathbf{~ c m}^{-\mathbf{1}} \mathbf{)}\end{array}$ & $\begin{array}{c}\text { Membrane } \\
\text { Samples }\end{array}$ & Electrolyte Uptake (\%) \\
\hline GPE-S $^{\mathrm{a}}$ & 0.0133 & 7.58 & MCM-S & $35.35 \pm 2.16$ \\
GPE-E $^{\mathrm{b}}$ & 0.0157 & 2.25 & MCM-E & $8.84 \pm 1.15$ \\
GPE-H $^{\mathrm{c}}$ & 0.0168 & 8.40 & MCM-H & $61.03 \pm 2.80$ \\
GPE-C $^{\mathrm{d}}$ & 0.0138 & 9.40 & MCM-C & $49.27 \pm 1.68$ \\
\hline
\end{tabular}

${ }^{\mathrm{a}}$ Gel polymer electrolyte with MCM-S; ${ }^{\mathrm{b}}$ Gel polymer electrolyte with MCM-E; ${ }^{\mathrm{c}}$ Gel polymer electrolyte with MCM-H; ${ }^{d}$ Gel polymer electrolyte with MCM-C.

As a natural polymer material, SPI has poor water resistance. To study the water resistance of SPI membranes, the membrane samples were submerged in deionized water for $24 \mathrm{~h}$ as shown in Figure $5 \mathrm{~d}$. MCM-S has been excessively swollen and almost lost its mechanical strength. Conversely, MCM-E and MCM-H exhibited better stability in deionized water.

\subsection{Electrochemical Performance of SSCs}

The electrochemical performance of SSCs was explored by EIS, CV and GCD techniques. For comparison, the electrochemical performance of SSC with GPE-C was also investigated. Nyquist plots of SSC-X (SSCs with different GPEs) in the frequency range of $0.01 \mathrm{~Hz}-100 \mathrm{kHz}$ was shown in Figure 6. The intercept with real axis ( $Z^{\prime}$ axis) in the high frequency region $\left(Z^{\prime \prime}=0\right)$ reflects equivalent series resistance $\left(R_{S}\right)$ of SSC cells, which is associated with the ionic resistance of the electrolyte, the intrinsic resistance of the electrode material and the contact resistance at the interface of electrode material [47-49]. An approximate semicircular behavior at the high to medium frequency region refers to the interfacial charge transfer resistance $\left(R_{c t}\right)$, which is related to the process at the electrolyte/electrode interface [50]. A slope line at medium frequency region is related to diffusion of 
the electrolyte, its length depends on the frequency of electrolyte ions transporting between electrode and polymer electrolyte [51]. The straight line nearly vertical to the axis at low frequency region indicates excellent capacitive behavior of the SSC cells [52]. Electrostatic diffusion capacity and overall capacitance behavior of SSCs assembled by SPI membranes are superior to SSC assembled with GPE-C. Various electrical parameters of SSC-E associated with bulk properties of electrolyte and electrode-electrolyte interface in different frequency ranges are worse than SSC-S. This is because crosslinked structures consume a large number of hydrophilic groups in the SPI and reduce the electrolyte uptake of MCM-E. Conversely, SSC-H exhibits a similar $R_{s}$ with SSC-S and shows a better capacitive behavior than SSC-S. HEC in GPE-H is beneficial for absorption of liquid electrolyte and the transport of ions, and the moderate swelling of GPE-H caused by HEC improves the interface performance and promotes the transport of ions at the electrode-electrolyte interface. Compared with SSC-H, SSC-C assembled with GPE-C shows a low $R_{S}$ due to its high ionic conductivity, however, SSC-C exhibits a larger ion transfer resistance between GPE-C and electrodes than SSC-H since MCM cannot be swelled by electrolyte, which results in a worse electrochemical performance than SSC-H.
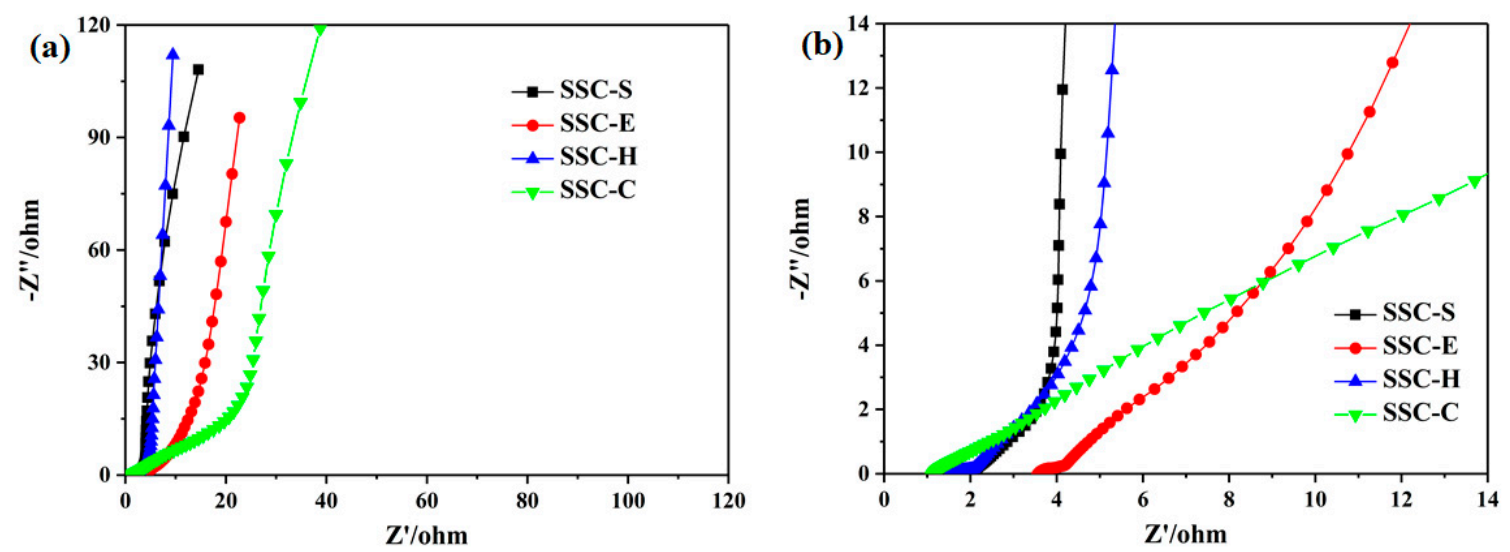

Figure 6. (a) Nyquist plots of SSCs in the frequency range of $0.01 \mathrm{~Hz}-100 \mathrm{kHz},(\mathbf{b})$ the high frequency region of the Nyquist plots.

CV curves of SSCs at scan rates of 20 and $100 \mathrm{mV} \mathrm{s}^{-1}$ are shown in Figure 7a,b, respectively. All curves of SSCs have similar rectangular profiles, symmetric with respect to the $\mathrm{X}$ axis and without redox peaks. The CV curves of SSC-C and SSC-E deviate significantly from the rectangle, while those of SSC-S and SSC-H still maintain a good rectangular at high scan rates. In addition, integral area of the curves of SSC-S and SSC-H are almost overlapping, which are far greater than those of SSC-E and SSC-C, demonstrating that the SSC-S and SSC-H exhibit similar capacitance behaviors better than SSC-E and SSC-C. The result further illustrates that the introduction of HEC in GPE-H improved the electrolyte uptake and accelerated the transport of electrolyte ions at the electrode-electrolyte interface, which elevated the capacitance of SSC-H. CV curves of SSC-H at different scan rates $\left(10-200 \mathrm{mV} \mathrm{s}^{-1}\right)$, as depicted in Figure 7c, showed only a slight deviation from perfect rectangular even at high scan rate of $200 \mathrm{mV} \mathrm{s}^{-1}$, which indicated that the capacitive behavior of SSC-H belongs to electrical double-layer formation and SSC-H had lower internal resistance. HEC in MCM-H accelerates transport of the electrolyte ions and reduces the equivalent series resistance of the GPE-H, which endows SSC with a higher specific capacitance and a better power performance. 

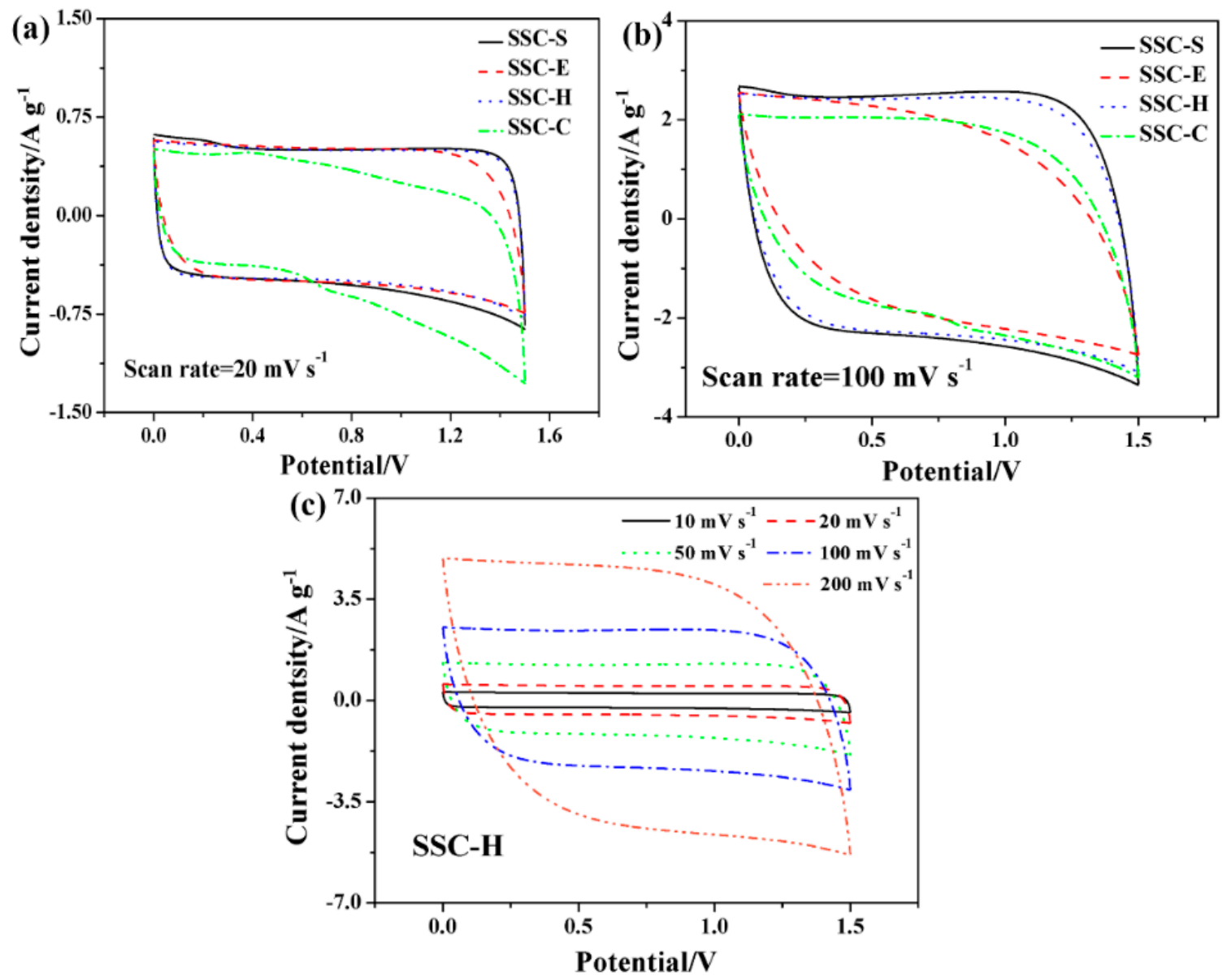

Figure 7. (a) CV curves of SSCs at scan rate of $20 \mathrm{mV} \mathrm{s}^{-1}$ and (b) $100 \mathrm{mV} \mathrm{s}^{-1}$, (c) CV curves of SSC-H at various scan rates.

GCD curves of SSCs at the current density of $1 \mathrm{~A} \mathrm{~g}^{-1}$ are shown in Figure 8a. The curves of SSC-S and SSC-H exhibited an ideal linear profile, the charge curves were almost perfectly symmetrical with their corresponding discharge curve within the potential window (0-1.5 V). However, the GCD curves of SSC-E and SSC-C deviate from the ideal symmetrical triangle, which indicates that SSC-H has superior electrical double layer capacitance characteristics and reversibility of charge and discharge over SSC-E and SSC-C. The GCD curves of SSC-H at different current densities (1-10 A g $\left.{ }^{-1}\right)$ are shown in Figure 8b. The GCD curve of SSC-H still maintains a symmetrical linear shape even at high current density, which further demonstrates that SSC-H has a good reversibility charge and discharge. $C_{s p}$ and voltage drop $\left(V_{d r o p}, \mathrm{~V}\right)$ of the SSC-X were calculated according to the discharge profile and demonstrated in Figure $8 \mathrm{c}$. The $C_{s p}$ of SSC-S and SSC-H decreased slightly and the $V_{\text {drop }}$ increased with the increase of current density due to internal resistance of SSCs. However, the $C_{s p}$ of SSC-E and SSC-C are greatly reduced and the $V_{\text {drop }}$ increase substantially with the increase of current density. This demonstrates that SSC-H has a better reversibility of charge and discharge and small internal resistance, which indicates that GPE-H can accelerates the transport of electrolyte ions and reduces the internal resistance of SSC-H due to the introduction of HEC. The $C_{s p}$ value of SSC-H was $98.91 \mathrm{~F} \mathrm{~g}^{-1}$ which is much higher than that of SSC-C $\left(86.22 \mathrm{~F} \mathrm{~g}^{-1}\right)$ at a current density of $1 \mathrm{~A} \mathrm{~g}^{-1}$. Even at high current densities of $5 \mathrm{~A} \mathrm{~g}^{-1}$, the $C_{s p}$ of SSC-H can reach $91.79 \mathrm{~F} \mathrm{~g}^{-1}$, whereas the sharp decay of $C_{s p}$ of SSC-C with commercial membrane MCM-C is only $69.9 \mathrm{~F} \mathrm{~g}^{-1}$. The $C_{s p}, E_{\text {cell }}$, and $P_{\text {cell }}$ of SSC-H were calculated at different current densities and listed in Table 3. 

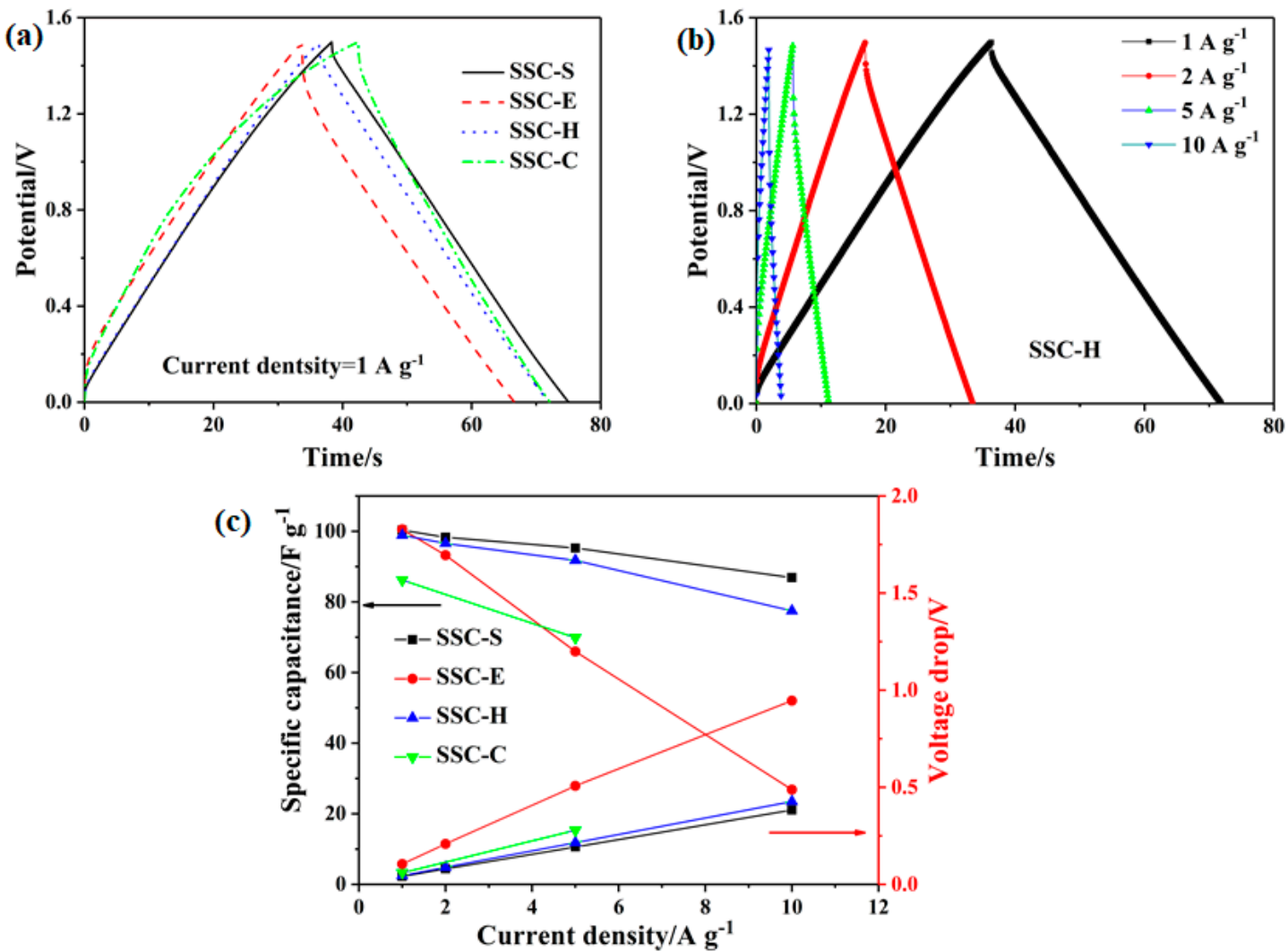

Figure 8. (a) GCD curves of SSCs at the current density of $1 \mathrm{~A} \mathrm{~g}^{-1}$, (b) GCD curves of SSC-H at various current densities, (c) specific capacitance and voltage drop of SSCs at various current density.

Table 3. Specific capacitance, energy density, and power density of SSCs at different current densities.

\begin{tabular}{|c|c|c|c|c|}
\hline Sample & $\begin{array}{l}\text { Current Density } \\
\left(\mathrm{A} \mathrm{g}^{-1}\right)\end{array}$ & $\begin{array}{c}\text { Specific Capacitance }\left(C_{s p},\right. \\
\left.\mathbf{F ~}^{-1}\right)\end{array}$ & $\begin{array}{l}\text { Energy Density } \\
\left(E_{\text {cell }}, \mathrm{W} \mathrm{h} \mathrm{kg}^{-1}\right)\end{array}$ & $\begin{array}{l}\text { Power Density } \\
\left(P_{\text {cell }}, \mathrm{W} \mathrm{kg}^{-1}\right)\end{array}$ \\
\hline \multirow{2}{*}{ SSC-S a } & 1 & 100.35 & 7.84 & 771.15 \\
\hline & 5 & 95.27 & 7.44 & 5351.76 \\
\hline \multirow{2}{*}{$S S C-E^{b}$} & 1 & 100.55 & 7.86 & 862.68 \\
\hline & 5 & 65.98 & 5.15 & 6621.43 \\
\hline \multirow{2}{*}{$\mathrm{SSC}-\mathrm{H}^{\mathrm{c}}$} & 1 & 98.91 & 7.73 & 786.10 \\
\hline & 5 & 91.79 & 7.17 & 4780.00 \\
\hline \multirow{2}{*}{ SSC-C ${ }^{d}$} & 1 & 86.22 & 6.74 & 786.89 \\
\hline & 5 & 69.9 & 5.46 & 5312.43 \\
\hline
\end{tabular}

a Solid-state supercapacitor with GPE-S; ${ }^{\text {b }}$ Solid-state supercapacitor with GPE-E; ${ }^{\text {c }}$ Solid-state supercapacitor with

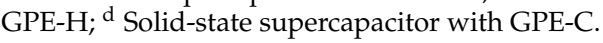

Flexibility is a crucial parameter for SSCs applied in wearable electronic devices and portable devices. The electrochemical performance of SSC- $\mathrm{H}^{\prime}$ was systematically measured under different bending angles as shown in Figure 9. The resulting CV curves, GCD curves and EIS curves with the bending angles of $0^{\circ}, 30^{\circ}, 45^{\circ}, 90^{\circ}$, and $180^{\circ}$ are shown in Figure $9 \mathrm{a}-\mathrm{e}$, respectively. Figure $9 \mathrm{f}$ is physical pictures of the various angles in the experiment. From the Nyquist plots in Figure $9 a, b$, it is known that at different angles, there is a small equivalent series resistance in the high frequency region, indicating that the bend has little effect on the equivalent series resistance; a vertical line close to $90^{\circ}$ is shown in the low frequency region, indicating that the bend has almost no effect on the interface change between GPE-H and the electrode. The almost overlap CV and GCD curves for SSC- $\mathrm{H}^{\prime}$ at different bending angles are obtained from the Figure $9 c-e$. Figure $9 b$ presents the analogous CV responses and area. The as-measured GCD curves in Figure 9d,e show a negligible change at different bending angles at a current density of $1.0 \mathrm{~A} \mathrm{~g}^{-1}$ and $5.0 \mathrm{~A} \mathrm{~g}^{-1}$. The approximate EIS, CV, and GCD 
curves at different angles reveal good angle stability and ideal flexibility of SSC- $\mathrm{H}^{\prime}$ for application in flexible electronic devices.
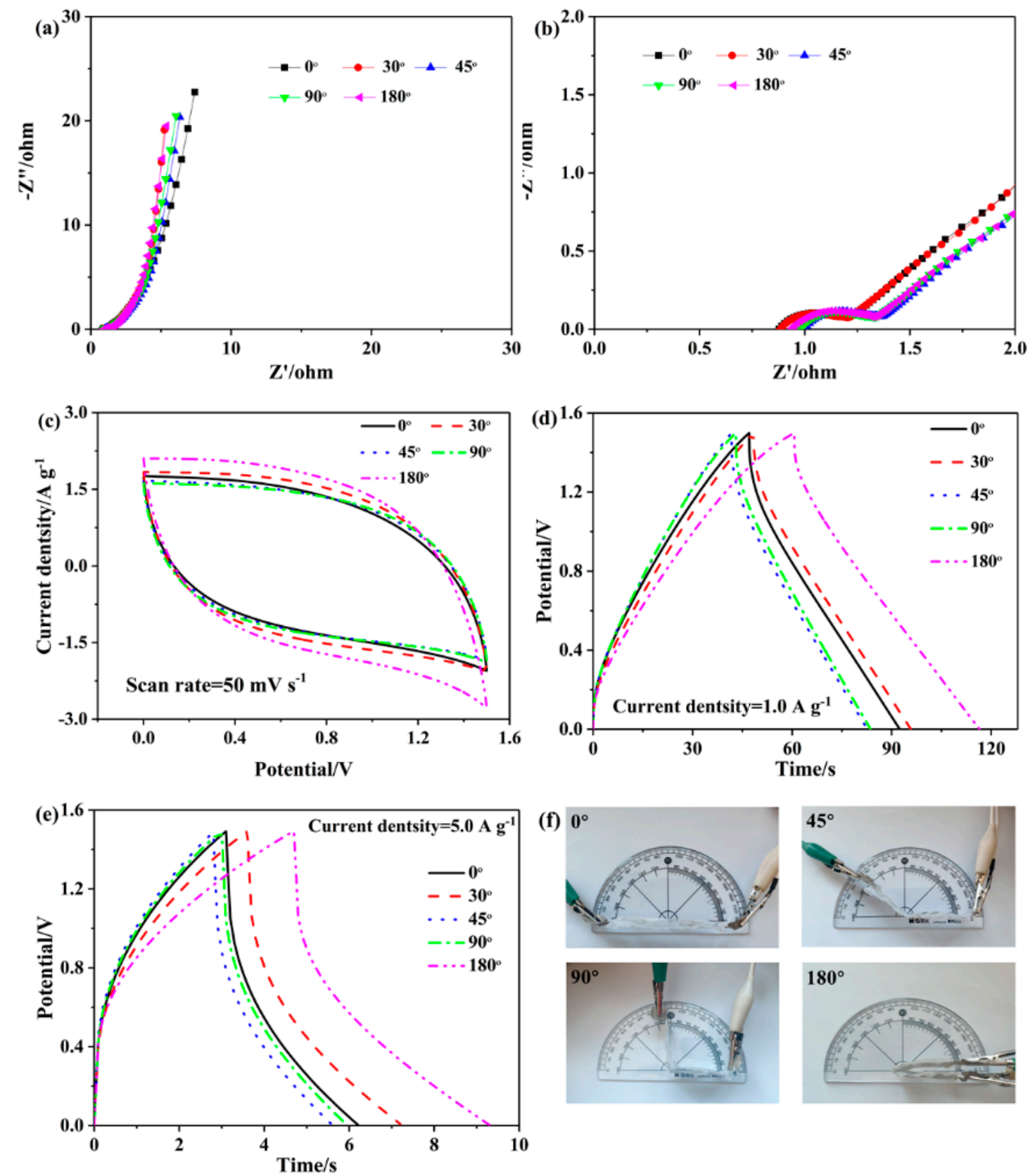

Figure 9. Electrochemical properties of SSC-H under various bending angles. (a) Nyquist plots in a frequency range from $0.01 \mathrm{~Hz}$ to $100 \mathrm{kHz},(\mathbf{b})$ Nyquist plots in the high frequency region, (c) CV curves at a scan rate of $50 \mathrm{mV} \mathrm{s}^{-1}$, (d) GCD curves at a current density of $1.0 \mathrm{~A} \mathrm{~g}^{-1}$, (e) at a current density of $5.0 \mathrm{~A} \mathrm{~g}^{-1}$, and (f) picture of various bending angles.

Two SSC-H cells connected in series and parallel were evaluated by CV and GCD measurements as shown in Figure 10a,b. Two SSC-H cells could be connected in series or in parallel and obtain a device that outputted approximately twice the potential, or twice the current density and charge-discharge time of the single SSC-H. As shown in Figure 10c, the $2 \mathrm{~V}$ light-emitting diode (LED) could be lighted up by three SSC-H cells in series connection, which indicated their good practical prospects. 

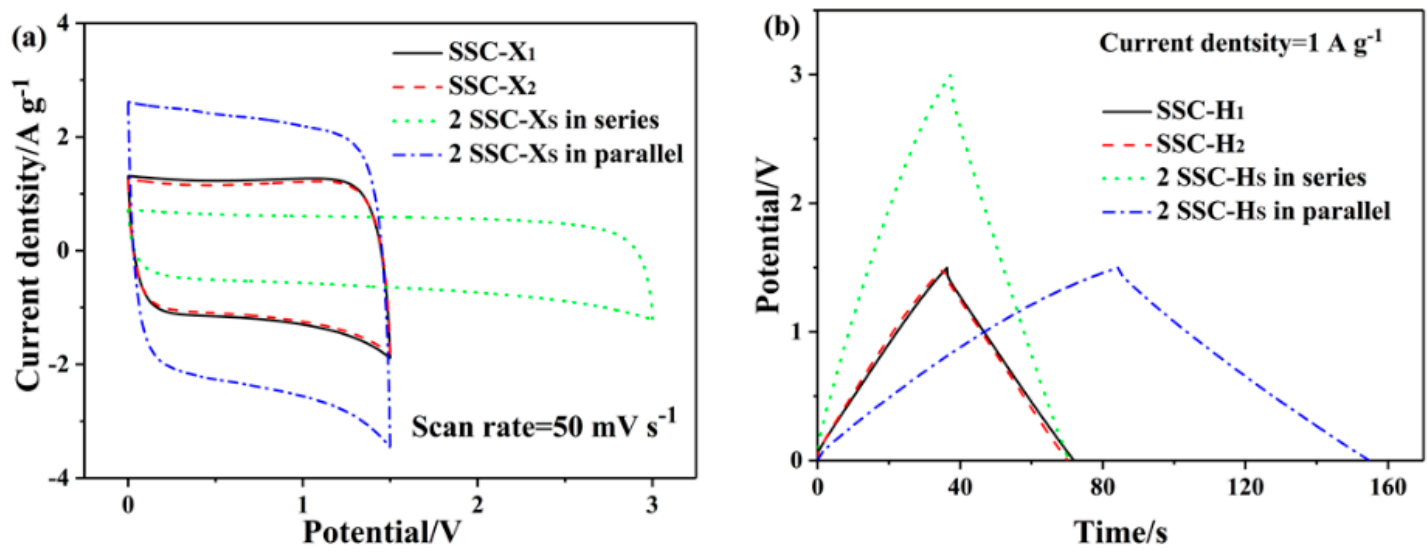

(c)

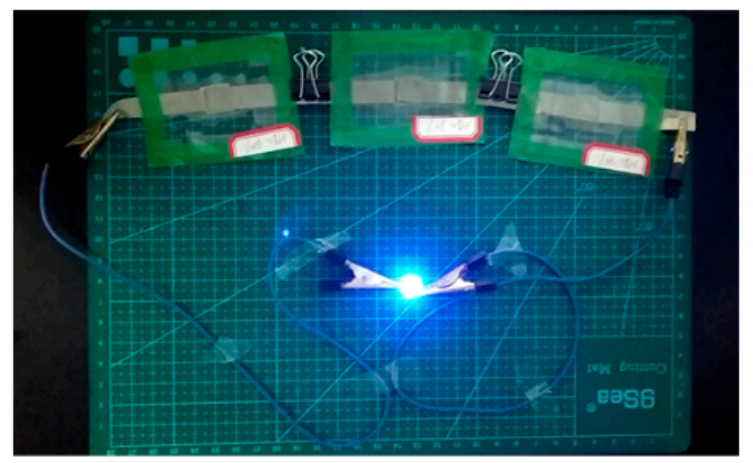

Figure 10. (a) CV curves of two SSC-Hs connected in series and in parallel at a scan rate of $50 \mathrm{mV}$ $\mathrm{s}^{-1}$, (b) GCD curves of two SSC-Hs connected in series and in parallel at current density of $1 \mathrm{~A} \mathrm{~g}^{-1}$, (c) photograph of the LED powered by three SSC-Hs connected in series.

The long cycle life of SSCs is one of the most important factors with regard to its practical application. To investigate the cycling stability, the SSC-H cell was tested at a constant current density of $2 \mathrm{~A} \mathrm{~g}^{-1}$ over 5000 continuous cycles. Figure 11 exhibits the variation of the coulombic efficiency and cycling retention as a function of the charge-discharge cycle numbers and the first 10th and last 10th charge-discharge curves of SSC-H are displayed in the inset of Figure 11. The coulombic efficiency calculated from the ratio of the discharge capacitance to the charge capacitance, maintained almost as high as $100 \%$ for 5000 cycles, which indicates that SSC-H has good charge and discharge reversibility. Even though the cycle retention shows a slight fluctuation in the early stage of charge-discharge, it remained almost 100\% even after 5000 cycles. The GCD curves still maintain a good symmetrical and linear shape and are almost the same as the initial GCD curves indicating an excellent electric double layer capacitive behavior and cycle stability of SSC-H. 


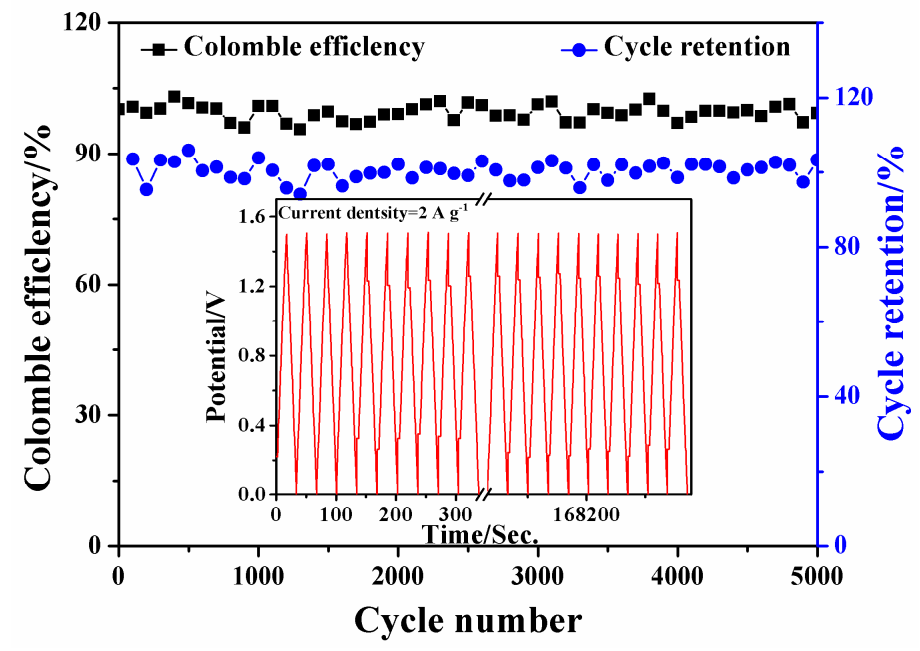

Figure 11. Cycle stability of SSC-H at a current density of $2.0 \mathrm{~A} \mathrm{~g}^{-1}$.

\section{Conclusions}

A transparent, flexible, biodegradable membrane based on crosslinked SPI and hydrophilic HEC was successfully prepared, and the GPE-H was obtained by the membrane saturated with $1 \mathrm{M} \mathrm{Li}_{2} \mathrm{SO}_{4}$. The water resistance of the MCM-E is significantly improved due to the crosslinked structure of the membranes. However, the ionic conductivity of GPE-E is reduced. The addition of the HEC not only improves the water resistance of the MCM-H, but also facilitates the transport of electrolyte ions for GPE-H. The electrochemical performance of SSCs assembled from SPI composite membranes were higher than that of SSC assembled by commercial aqueous PP/PE membrane. SSC-H assembled with GPE-H exhibits a high capacitance of $91.79 \mathrm{~F} \mathrm{~g}^{-1}$ and an energy density of $7.17 \mathrm{~W}$ $\mathrm{h} \mathrm{kg}^{-1}$ at a current density of $5 \mathrm{~A} \mathrm{~g}^{-1}$, which is much higher than SSC-E assembled with GPE-E. According to the experiments at various angles, it was proved that SSC- $\mathrm{H}^{\prime}$ fabricated with GPE-H has good flexibility. The solid-state supercapacitors also show considerable application performance at series a parallel connection condition. Electrochemical cycle performance of the SSC-H indicated almost $100 \%$ cycling retention and near $100 \%$ coulombic efficiency over 5000 charge-discharge cycles at $2 \mathrm{~A} \mathrm{~g}^{-1}$. The results obtained in this work confirm that GPEs based on renewable, degradable biomass material are interesting candidates for replacing liquid electrolytes for flexible solid-state devices. Further investigations on regulating composition structure of gel polymer electrolyte based on SPI/HEC system to optimize the mechanical stability and improve the electrochemical performance such as energy density and specific capacitance are currently in progress.

Author Contributions: Z.X.: Validation, Conceptualization, Investigation, Writing-original draft, Writing-review and editing. S.N.: Validation, Conceptualization, Investigation, Writing-original draft, Writing-review and editing. Z.G.: Supervision, Resources. Y.Z.: Software, Formal analysis. J.G.: Supervision, Project administration. P.H.: Formal analysis, Writing-review and editing, Project administration, Funding acquisition.

Funding: This research was funded by the National Natural Science Foundation of China (grant nos. 51603032 and 31870542), the Fundamental Research Funds for the Central Universities (grant nos. 2572018BB01, 2572018CP01, and 2572017EB06) and Postdoctoral Science Foundation of China (grant no. 2017M621230).

Conflicts of Interest: The authors declare no conflict of interest.

\section{References}

1. Li, Z.; Jiao, X.; Li, C.; Chen, D. Synthesis and application of nanocages in supercapacitors. Chem. Eng. J. 2018, 351, 135-156. [CrossRef] 
2. Na, R.; Lu, N.; Zhang, S.; Huo, G.; Yang, Y.; Zhang, C.; Mu, Y.; Luo, Y.; Wang, G. Facile synthesis of a high-performance, fire-retardant organic gel polymer electrolyte for flexible solid-state supercapacitors. Electrochim. Acta 2018, 290, 262-272. [CrossRef]

3. Young, C.; Salunkhe, R.R.; Tang, J.; Hu, C.C.; Shahabuddin, M.; Yanmaz, E.; Hossain, M.S.A.; Kim, J.H.; Yamauchi, Y. Zeolitic imidazolate framework (ZIF-8) derived nanoporous carbon: The effect of carbonization temperature on the supercapacitor performance in an aqueous electrolyte. Phys. Chem. Chem. Phys. 2016, 18, 29308-29315. [CrossRef] [PubMed]

4. Chen, Y.; Liu, F.; Qiu, F.; Lu, C.; Kang, J.; Zhao, D.; Han, S.; Zhuang, X. Cobalt-Doped Porous Carbon Nanosheets Derived from 2D Hypercrosslinked Polymer with $\mathrm{CoN}_{4}$ for High Performance Electrochemical Capacitors. Polymers 2018, 10, 1339. [CrossRef] [PubMed]

5. Pant, B.; Park, M.; Park, S.J. TiO 2 NPs Assembled into a Carbon Nanofiber Composite Electrode by a One-Step Electrospinning Process for Supercapacitor Applications. Polymers 2019, 11, 899. [CrossRef]

6. Olejnik, P.; Gniadek, M.; Echegoyen, L.; Plonska-Brzezinska, M.E. Nanoforest: Polyaniline Nanotubes Modified with Carbon Nano-Onions as a Nanocomposite Material for Easy-to-Miniaturize High-Performance Solid-State Supercapacitors. Polymers 2018, 10, 1408. [CrossRef]

7. Tan, S.; Li, J.; Zhou, L.; Chen, P.; Shi, J.; Xu, Z. Modified carbon fiber paper-based electrodes wrapped by conducting polymers with enhanced electrochemical performance for supercapacitors. Polymers 2018, 10, 1072. [CrossRef]

8. Huang, H.S.; Chang, K.H.; Suzuki, N.; Yamauchi, Y.; Hu, C.C.; Wu, K.C.W. Evaporation-Induced Coating of Hydrous Ruthenium Oxide on Mesoporous Silica Nanoparticles to Develop High-Performance Supercapacitors. Small 2013, 9, 2520-2526. [CrossRef]

9. Makino, S.; Yamauchi, Y.; Sugimoto, W. Synthesis of electro-deposited ordered mesoporous $\mathrm{RuO}_{\mathbf{x}} \mathrm{using}$ lyotropic liquid crystal and application toward micro-supercapacitors. J. Power Sources 2013, 227, 153-160. [CrossRef]

10. Bastakoti, B.P.; Huang, H.S.; Chen, L.C.; Wu, K.C.W.; Yamauchi, Y. Block copolymer assisted synthesis of porous $\alpha-\mathrm{Ni}(\mathrm{OH})_{2}$ microflowers with high surface areas as electrochemical pseudocapacitor materials. Chem. Commun. 2012, 48, 9150-9152. [CrossRef]

11. Xia, L.; Yu, L.; Hu, D.; Chen, G.Z. Electrolytes for electrochemical energy storage. Mater. Chem. Front. 2017, 1, 584-618. [CrossRef]

12. Na, R.; Su, C.W.; Su, Y.H.; Chen, Y.C.; Chen, Y.M.; Wang, G.; Teng, H. Solvent-free synthesis of an ionic liquid integrated ether-abundant polymer as a solid electrolyte for flexible electric double-layer capacitors. J. Mater. Chem. A 2017, 5, 19703-19713. [CrossRef]

13. Na, R.; Huo, G.; Zhang, S.; Huo, P.; Du, Y.; Luan, J.; Zhu, K.; Wang, G. A novel poly (ethylene glycol)-grafted poly (arylene ether ketone) blend micro-porous polymer electrolyte for solid-state electric double layer capacitors formed by incorporating a chitosan-based $\mathrm{LiClO}_{4}$ gel electrolyte. J. Mater. Chem. A 2016, 4, 18116-18127. [CrossRef]

14. Lu, X.; Yu, M.; Wang, G.; Tong, Y.; Li, Y. Flexible solid-state supercapacitors: Design, fabrication and applications. Energy Environ. Sci. 2014, 7, 2160-2181. [CrossRef]

15. Deng, R.; Xia, Z.; Sun, R.; Wang, S.; Sun, G. Nanostructured ultrathin catalyst layer with ordered platinum nanotube arrays for polymer electrolyte membrane fuel cells. J. Energy Chem. 2019, 43, 33-39. [CrossRef]

16. Piana, G.; Bella, F.; Geobaldo, F.; Meligrana, G.; Gerbaldi, C. PEO/LAGP hybrid solid polymer electrolytes for ambient temperature lithium batteries by solvent-free, "one pot" preparation. J. Energy Storage 2019, 26, 100947. [CrossRef]

17. Falco, M.; Simari, C.; Ferrara, C.; Nair, J.R.; Meligrana, G.; Bella, F.; Nicotera, I.; Mustarelli, P.; Winter, M.; Gerbaldi, C. Understanding the effect of UV-induced crosslinking on the physico-chemical properties of highly performing PEO/LiTFSI-based polymer electrolytes. Langmuir 2019, 35, 8210-8219. [CrossRef]

18. Wang, X.; Hao, X.; Cai, D.; Zhang, S.; Xia, X.; Tu, J. An ultraviolet polymerized 3D gel polymer electrolyte based on multi-walled carbon nanotubes doped double polymer matrices for lithium-sulfur batteries. Chem. Eng. J. 2019, 382, 122714. [CrossRef]

19. Xun, Z.; Liu, Y.; Gu, J.; Liu, L.; Huo, P. A Biomass-Based Redox Gel Polymer Electrolyte for Improving Energy Density of Flexible Supercapacitor. J. Electrochem. Soc. 2019, 166, A2300-A2312. [CrossRef]

20. Wang, Y.; Qiao, X.; Zhang, C.; Zhou, X. Development of structural supercapacitors with epoxy based adhesive polymer electrolyte. J. Energy Storage 2019, 26, 100968. [CrossRef]

21. Wang, Y.; Zhong, W.H.; Schiff, T.; Eyler, A.; Li, B. A Particle-Controlled, High-Performance, Gum-Like Electrolyte for Safe and Flexible Energy Storage Devices. Adv. Energy Mater. 2015, 5, 1400463. [CrossRef] 
22. Moon, W.G.; Kim, G.P.; Lee, M.; Song, H.D.; Yi, J. A Biodegradable Gel Electrolyte for Use in High-Performance Flexible Supercapacitors. ACS Appl. Mater. Interfaces 2015, 7, 3503-3511. [CrossRef] [PubMed]

23. Sekhon, S.S. Conductivity behaviour of polymer gel electrolytes: Role of polymer. Bull. Mater. Sci. 2003, 26, 321-328. [CrossRef]

24. Meng, C.; Liu, C.; Chen, L.; Hu, C.; Fan, S. Highly flexible and all-solid-state paperlike polymer supercapacitors. Nano Lett. 2010, 10, 4025-4031. [CrossRef] [PubMed]

25. Osada, I.; Vries, H.; Scrosati, B.; Passerini, S. Ionic-Liquid-Based Polymer Electrolytes for Battery Applications. Angew. Chem. Int. Ed. 2016, 55, 500-513. [CrossRef] [PubMed]

26. Kalhoff, J.; Eshetu, G.G.; Bresser, D.; Passerini, S. Safer electrolytes for lithium-ion batteries: State of the art and perspectives. ChemSusChem 2015, 8, 2154-2175. [CrossRef]

27. Tan, S.; Ji, Y.J.; Zhang, Z.R.; Yang, Y. Recent Progress in Research on High-Voltage Electrolytes for Lithium-Ion Batteries. ChemPhysChem 2014, 15, 1956-1969. [CrossRef]

28. Jiang, M.; Zhu, J.; Chen, C.; Lu, Y.; Ge, Y.; Zhang, X. Poly (vinyl alcohol) borate gel polymer electrolytes prepared by electrodeposition and their application in electrochemical supercapacitors. ACS Appl. Mater. Interfaces 2016, 8, 3473-3481. [CrossRef]

29. Kalpana, D.; Renganathan, N.G.; Pitchumani, S. A new class of alkaline polymer gel electrolyte for carbon aerogel supercapacitors. J. Power Sources 2006, 157, 621-623. [CrossRef]

30. Cheng, X.; Pan, J.; Zhao, Y.; Liao, M.; Peng, H. Gel Polymer Electrolytes for Electrochemical Energy Storage. Adv. Energy Mater. 2018, 8, 1702184. [CrossRef]

31. Ponez, L.; Sentanin, F.C.; Majid, S.R.; Arof, A.K.; Pawlicka, A. Ion-conducting membranes based on gelatin and containing LiI/ $\mathrm{I}_{2}$ for electrochromic devices. Mol. Cryst. Liq. Cryst. 2012, 554, 239-251. [CrossRef]

32. Ma, L.; Yang, Y.; Yao, J.; Shao, Z.; Chen, X. Robust soy protein films obtained by slight chemical modification of polypeptide chains. Polym. Chem. 2013, 4, 5425-5431. [CrossRef]

33. Wang, X.; Fu, X.; Wang, Y.; Zhong, W. A protein-reinforced adhesive composite electrolyte. Polymer 2016, 106, 43-52. [CrossRef]

34. Zhu, M.; Tan, C.; Fang, Q.; Gao, L.; Sui, G.; Yang, X. High performance and biodegradable skeleton material based on soy protein isolate for gel polymer electrolyte. ACS Sustain. Chem. Eng. 2016, 4, 4498-4505. [CrossRef]

35. Zhu, M.; Wu, J.; Zhong, W.H.; Lan, J.; Sui, G.; Yang, X. A Biobased Composite Gel Polymer Electrolyte with Functions of Lithium Dendrites Suppressing and Manganese Ions Trapping. Adv. Energy Mater. 2018, 8, 1702561. [CrossRef]

36. González, A.; Tártara, L.I.; Palma, S.D.; Igarzabal, C.I.A. Crosslinked soy protein films and their application as ophthalmic drug delivery system. Mater. Sci. Eng. C 2015, 51, 73-79. [CrossRef] [PubMed]

37. Boy, R.; Maness, C.; Kotek, R. Properties of chitosan/soy protein blended films with added plasticizing agent as a function of solvent type at acidic pH. Int. J. Polym. Mater. Polym. Biomater. 2016, 65, 11-17. [CrossRef]

38. Wang, L.; Li, J.; Zhang, S.; Shi, J. Preparation and characterization of all-biomass soy protein isolate-based films enhanced by epoxy castor oil acid sodium and hydroxypropyl cellulose. Materials 2016, 9, 193. [CrossRef]

39. Zhu, C.Y.; Liu, H.F.; Fu, M.; Zhao, X.H. Structure and property changes of soybean protein isolates resulted from the glycation and cross-linking by transglutaminase and a degraded chitosan. CyTA J. Food 2016, 14, 138-144. [CrossRef]

40. Huo, P.; Ni, S.; Hou, P.; Xun, Z.; Liu, Y.; Gu, J. A Crosslinked Soybean Protein Isolate Gel Polymer Electrolyte Based on Neutral Aqueous Electrolyte for a High-Energy-Density Supercapacitor. Polymers 2019, 11, 863. [CrossRef]

41. Zhou, J.; Qin, Y.; Liu, S.; Zhang, L. Homogenous synthesis of hydroxyethylcellulose in NaOH/urea aqueous solution. Macromol. Biosci. 2006, 6, 84-89. [CrossRef] [PubMed]

42. Zhao, Y.; He, M.; Zhao, L.; Wang, S.; Li, Y.; Gan, L.; Li, M.; Xu, L.; Chang, P.R.; Anderson, D.P.; et al. Epichlorohydrin-cross-linked hydroxyethyl cellulose/soy protein isolate composite films as biocompatible and biodegradable implants for tissue engineering. ACS Appl. Mater. Interfaces 2016, 8, 2781-2795. [CrossRef] [PubMed]

43. Ciannamea, E.M.; Stefani, P.M.; Ruseckaite, R.A. Physical and mechanical properties of compression molded and solution casting soybean protein concentrate based films. Food Hydrocoll. 2014, 38, 193-204. [CrossRef]

44. Lei, H.; Du, G.; Wu, Z.; Xi, X.; Dong, Z. Cross-linked soy-based wood adhesives for plywood. Int. J. Adhes. Adhes. 2014, 50, 199-203. [CrossRef]

45. Xu, F.; Dong, Y.; Zhang, W.; Zhang, S.; Li, L.; Li, J. Preparation of cross-linked soy protein isolate-based environmentally-friendly films enhanced by PTGE and PAM. Ind. Crop. Prod. 2015, 67, 373-380. [CrossRef] 
46. Chen, J.; Chen, X.; Zhu, Q.; Chen, F.; Zhao, X.; Ao, Q. Determination of the domain structure of the 7s and 11s globulins from soy proteins by XRD and FTIR. J. Sci. Food Agric. 2013, 93, 1687-1691. [CrossRef]

47. Tõnurist, K.; Thomberg, T.; Jänes, A.; Romann, T.; Sammelselg, V.; Lust, E. Influence of separator properties on electrochemical performance of electrical double-layer capacitors. J. Electroanal. Chem. 2013, 689, 8-20. [CrossRef]

48. Tu, Q.M.; Fan, L.Q.; Pan, F.; Huang, J.L.; Gu, Y.; Lin, J.M.; Huang, M.L.; Huang, Y.F.; Wu, J.H. Design of a novel redox-active gel polymer electrolyte with a dual-role ionic liquid for flexible supercapacitors. Electrochim. Acta 2018, 268, 562-568. [CrossRef]

49. Sun, X.; Zhang, X.; Zhang, H.; Zhang, D.; Ma, Y. A comparative study of activated carbon-based symmetric supercapacitors in $\mathrm{Li}_{2} \mathrm{SO}_{4}$ and $\mathrm{KOH}$ aqueous electrolytes. J. Solid State Electr. 2012, 16, 2597-2603. [CrossRef]

50. Yang, X.; Zhang, L.; Zhang, F.; Zhang, T.; Huang, Y.; Chen, Y. A high-performance all-solid-state supercapacitor with graphene-doped carbon material electrodes and a graphene oxide-doped ion gel electrolyte. Carbon 2014, 72, 381-386. [CrossRef]

51. Sun, X.Z.; Zhang, X.; Huang, B.; Ma, Y.W. Effects of separator on the electrochemical performance of electrical double-layer capacitor and hybrid battery-supercapacitor. Acta Phys. Chim. Sin. 2014, 30, 485-491. [CrossRef]

52. Pandey, G.P.; Hashmi, S.A. Performance of solid-state supercapacitors with ionic liquid 1-ethyl-3-methylimidazolium tris (pentafluoroethyl) trifluorophosphate based gel polymer electrolyte and modified MWCNT electrodes. Electrochim. Acta 2013, 105, 333-341. [CrossRef]

(C) 2019 by the authors. Licensee MDPI, Basel, Switzerland. This article is an open access article distributed under the terms and conditions of the Creative Commons Attribution (CC BY) license (http://creativecommons.org/licenses/by/4.0/). 